\title{
L'auteur à la Renaissance. "L'altro che è in noi», ouvrage édité par Rosanna Gorris Camos et Alexandre Vanautgaerden
}

Dario Cecchetti

\section{(2) OpenEdition}

\section{Journals}

\section{Edizione digitale}

URL: http://journals.openedition.org/studifrancesi/6256

DOI: 10.4000/studifrancesi.6256

ISSN: 2421-5856

\section{Editore}

Rosenberg \& Sellier

\section{Edizione cartacea}

Data di pubblicazione: 1 novembre 2010

Paginazione: $544-545$

ISSN: 0039-2944

\section{Notizia bibliografica digitale}

Dario Cecchetti, «L'auteur à la Renaissance. «L'altro che è in noi», ouvrage édité par Rosanna Gorris Camos et Alexandre Vanautgaerden», Studi Francesi [Online], 162 (LIV | III) | 2010, online dal 30 novembre 2015, consultato il 08 janvier 2021. URL: http://journals.openedition.org/studifrancesi/6256 ; DOI: https://doi.org/10.4000/studifrancesi.6256

Questo documento è stato generato automaticamente il 8 janvier 2021.

\section{cc) (†)}

Studi Francesi è distribuita con Licenza Creative Commons Attribuzione - Non commerciale - Non opere derivate 4.0 Internazionale. 


\title{
L'auteur à la Renaissance. «L'altro che è in noi», ouvrage édité par Rosanna Gorris Camos et Alexandre Vanautgaerden
}

\author{
Dario Cecchetti
}

\section{NOTIZIA}

AA. VV., L'auteur à la Renaissance. «L'altro che è in noi», ouvrage édité par Rosanna GORRIS CAMOS et Alexandre VANAUTGAERDEN, Turnhout, Brepols, 2009, pp. 655.

1 Il presente volume raccoglie le comunicazioni di due convegni (a Bruxelles e a Verona), organizzati congiuntamente dalla Maison d'Érasme e dal Gruppo di studio sul Cinquecento francese. In una prima sezione ci si interroga sull'identità dell'autore; la seconda sezione tratta del genere delle vite parallele; la terza sezione pone interrogativi sul tema dell"altro che è in noi' in autori come Sannazaro, Egidio da Viterbo, Erasmo ritrattista di Gerolamo, Erasmo biografo di Origene; la quarta sezione tratta degli specchi deformanti della polemica che accompagna lo scontro fra Alberto Pio ed Erasmo; la quinta sezione tratta delle Gallerie di uomini illustri, Da Vasari a Thevet; la sesta affronta il tema de claris mulieribus; un'ampia sezione, la settima, tratta della forma autobiografica; un'ultima sezione è consacrata a Montaigne.

2 I contributi qui raccolti sono i seguenti: Reinhard BoDENMANN, L'auteur et son nom de plume. Autopsie d'un choix: le cas des pays francophones et germanophones $d u \mathrm{XV}^{e}$ siècle (pp. 21-63), Malcolm WALSBY, La voix de l'auteur? Autorité et identité dans les imprimés français au XVI e siècle (pp. 67-81), Carlo VECCE, La «mort de l'auteur» à la Renaissance (pp. 85-99), Jeanine DE LANTSHEER, Le privilège: un droit de l'auteur ou de l'éditeur? À propos de Juste Lipse et de la publication de son ceuvre (pp. 103-121), Andrea RODIGHIERo, Noi non scriviamo storie, ma vite. Forme plutarchee della narrazione (pp. 127-143), Patricia EICHEL-LOJKINE, La fabrique 
du récit de vie au $\mathrm{XVI}^{e}$ siècle (pp. 147-165), Michel JEANNERET, Vies d'auteur. Sur le commentaire de Belleau au second livre des «Amours» de Ronsard (pp. 169-179), Marc DERAMAIX, 'Non voce pares'. Sannazar, Gilles de Viterbe et leurs doubles (pp. 185-218), Alexandre VANAUTGAERDEN, Portrait d'Érasme, 'pourtraict' de Jérôme (pp. 221-256), André GoDIN, Affinités patristiques et stratégies biographiques. La «Vita Origenis» d'Érasme (1536) (pp. 259-281), Nicolette BROUT, Andreas Schottus, traducteur et continuateur d'Antonio Agustín. Une polémique sur l'usage du vernaculaire (pp. 285-309), Fabio FORNER Erasmo e Alberto Pio. Biografia e autobiografia nello specchio deformante della polemica (pp 315-327), Marie THEUNISSEN-FAIDER, 'Sub euangelistae persona'. les «Paraphrases au Nouveau Testament» dans la polémique entre Érasme et Alberto Pio (pp. 331-345), Mario Pozzi, Dalle biografie alla storia. Le «Vite» di Giorgio Vasari (pp. 351-381), Frank LESTRINGANT, L'Illustre Thevet. «Les vrais pourtraits et vies des hommes Illustres» de 1584 (pp. 385-399), Dominique DE COURCELLES, Sor Isabel de Villena dans la Renaissance valencienne. S'écrire soi comme l'Autre (pp. 405-418), Mariangela MIOTTI, Episodi biblici, vite esemplari, eroine tragiche (pp. 421-438), Loris PETRIS, Entre patience et révolte. Figures de la 'pia vidua' chez les femmes Illustres de la Renaissance (pp. 441-465), Jean-Louis FOURNEL, Qu'est-ce qu'un homme d'État? Réflexions autobiographiques de Francesco Guicciardini (pp. 471-491), Alba CECCARELLI PELLEGRINO, Philibert De l'Orme, autobiografo. Dal 'mémoire' apologetico alle pagine di 'mémoires' nei Trattati (pp. 495-509), Nerina CLERICI BALMAS, Brantôme: un memorialista allo specchio (pp. 513-527), Davide BIGALLI, Autobiografia di una nazione. L'«evangelho portuguees» di Fernão Lopes (pp. 531-540), Magda CAMPANINI-CATANI, Le forme dell'io nella scrittura epistolare. Le raccolte di lettere tra modello retorico e invenzione letteraria (pp. 543-556), Vincenzo RosSIERCOLANI, L'io molteplice, l'io debole, l'io negativo. Cenni sulla natura e sull'origine del problema del soggetto nel pensiero rinascimentale (pp. 559-586), Concetta CAVALLINI, Le "Journal de Voyage» de Montaigne. Moi actif, moi passif, moi sujet/objet du récit (pp. 591-602), Valerio CORDINER, Échos d'histoires et voix de l'âme au château de Montaigne (pp. 605-622), Nicoletta PANICHI, 'Devenant toujours autre d'un autre'. Montaigne e la crisi del soggetto moderno tra ontologia e storia (pp. 625-655).

3 Attraverso, dunque, lo studio dell'autobiografia, della biografia, della polemica personale, della ritrattistica letteraria, viene messo in luce l'emergere dell'io' in differenti generi letterari - inteso anzitutto come autodisvelamento dell'autore - e si evidenzia come «il libro sia un'esperienza di spossesso e di sdoppiamento» e come, «se il libro è consustanziale al suo autore, possa comunque acquistare una sua autonomia $\mathrm{e}$ diventare un libro distinto dal suo autore; e la verità stessa si presenti come una contraddizione; e parimenti come la verità sia multipla e presenti volti multipli, una moltiplicazione e vicissitudine di forme, simile, nel libro, a un lavoro di intarsio» (R. Gorris Camos). 